\title{
Supramolecular columnar liquid crystals by hydrogen bonding between a clicked star-shaped s-triazine and benzoic acids
}

\author{
Beatriz Feringán, ${ }^{[a]}$ Pilar Romero, ${ }^{[a]}$ José Luis Serrano, ${ }^{[b]}$ Raquel Giménez ${ }^{*[a]}$ and Teresa Sierra*[a]
}

\begin{abstract}
A star-shaped tris(triazolyl)triazine is shown to establish $\mathrm{H}$-bond interactions with polycatenar benzoic acids. The formation of $\mathrm{H}$-bonded triazine:acid complexes has been proved in solution and in bulk by different techniques. All the complexes, mainly formed by non-mesogenic components, show enantiotropic hexagonal columnar mesomorphism, which relies on the formation of $\mathrm{H}$-bond complexes in a 1:3 ratio, triazine:acid. This approach combines the easy synthesis of a non-mesomorphic triazine core by click chemistry, and the preparation of a supramolecular complex, providing a much more straightforward way than covalent synthesis to modify the periphery of triazine discotics in order to modulate their functionality.
\end{abstract}

\section{Introduction}

Since the earlier examples, ${ }^{[1]}$ supramolecular liquid crystals, and in particular the ones showing columnar arrangements, are considered a useful strategy to develop structural complexity and ordered functional materials. ${ }^{[2]}$ These systems are able to form the same liquid crystal phases as covalent liquid crystals but, generally, they are much easier to prepare, as smaller building blocks self-assemble spontaneously to give the columnar arrangements. In addition, they are dynamic systems, allowing a fast response to external stimuli.

One approach to obtain supramolecular columnar liquid crystals is by $\mathrm{H}$-bonding of a heterocyclic core that does not show the columnar phase with complementary peripheral units, such as some readily accessible promesogenic carboxylic acids. ${ }^{[3]}$ Up to our knowledge, there are only a few examples following this method, ${ }^{[4]}$ although it is an interesting strategy to access novel functional columnar nanostructures when a $\pi$ conjugated core is used. ${ }^{[5]}$ Therefore, in order to obtain novel supramolecular columnar liquid crystals by interaction with carboxylic acids, novel discotic building blocks able to interact through $\mathrm{H}$-bonding are necessary. In this line, the $\mathrm{H}$-bonding ability of a novel $\pi$-functional core bearing triazine and triazole rings is studied here.

[a] B. Feringán, Dr. P. Romero, Dr. R. Giménez, Dr. T. Sierra Departamento de Química Orgánica

Instituto de Ciencia de Materiales de Aragón

Universidad de Zaragoza-CSIC, 50009, Zaragoza, Spain

F-mail: rgimenez@unizares, tsierra@unizares

[b] Prof. J. L. Serrano

Departamento de Química Orgánica

Instituto de Nanociencia de Aragón

Universidad de Zaragoza, 50018, Zaragoza, Spain

Supporting information for this article is given via a link at the end of the document.
The 1,3,5-triazine ring (s-triazine) is a star-shaped $\pi$ functional unit $^{[6]}$ that has been used to obtain columnar liquid crystals. ${ }^{[7]}$ In addition, triazine-based cores, such as triarylaminotriazine ${ }^{[8]}$ or $\mathrm{N}$-alkylmelamine derivatives,${ }^{[9]}$ can also form $\mathrm{H}$-bonds with carboxylic acids providing columnar mesomorphic behavior. Additionally, the 1,2,3-triazole ring, easily accessible through click chemistry, ${ }^{[10]}$ is very attractive for functional materials, ${ }^{[11]}$ and also considering supramolecular interactions. ${ }^{[12]}$ The formation of $\mathrm{H}$-bonds between 1,2,3-triazole and anions is well-known, ${ }^{[13]}$ but this ring can also form $\mathrm{H}$-bonds with carboxylic acids. ${ }^{[4,, e, 14]}$ For example, H-bonded complexes consisting of a $\mathrm{C}_{3}$-symmetric tris(triazolyl)benzene unit with benzoic acids in a 1:3 stoichiometry which show columnar mesomorphism have recently been described. ${ }^{[\mathrm{d}]}$ Moreover, click chemistry allows the appropriate modification of the periphery of the molecules to obtain discotic liquid crystals. ${ }^{[15]}$ Indeed, the versatile 1,3,5-triazine scaffold can be triply functionalized with triazole rings by click chemistry to give the star-shaped 2,4,6tris(triazolyl)-1,3,5-triazine. ${ }^{[16]}$ This core can be readily prepared and gives rise to derivatives with columnar mesomorphism. ${ }^{[16-17]}$

In the present work, we go a step further and explore the ability of this core to form $\mathrm{H}$-bonds because of the presence of triazine and triazole rings. In particular, we study the formation of supramolecular $\mathrm{H}$-bonded complexes between a tris(triazolyl)triazine derivative and several benzoic acids in order to obtain columnar liquid crystals which could be, in this way, easily modulated in their periphery.

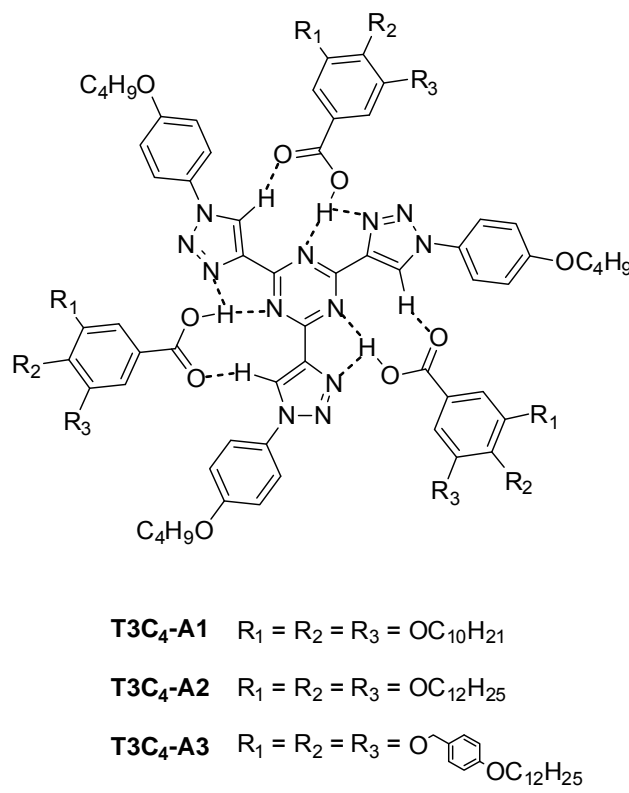

Figure 1. Molecular structure of the target supramolecular complexes. 
The tris(triazolyl)triazine derivative used as a core $\left(\mathrm{T}_{3} \mathrm{C}_{4}\right)$ has a $p$-butoxyphenyl substituent in each triazole ring (Scheme 1 ) and it is not a liquid crystal. The butoxy terminal chains favor the solubility in organic solvents, which is important for the formation of the supramolecular complexes by dissolution of a mixture of the components.

In order to study the formation of the supramolecular complexes and the induction of columnar mesomorphism, three 3,4,5-trisubstituted benzoic acids have been used. Two of them bear three alkoxy chains of ten carbon atoms (A1) or twelve carbon atoms (A2), which allows comparing the influence of the length of the alkoxy chains on the stability of the complex. The third acid is a benzoic acid with three alkoxy terminal chains of twelve carbon atoms in a dendron-like aromatic core (A3).

By using the $\mathrm{T}_{3} \mathrm{C}_{4}$ core and these carboxylic acids, mixtures of $1: 3$ stoichiometry have been prepared. The structure of the target supramolecular complexes is shown in Figure 1. Besides the $\mathrm{H}$-bond between the hydroxyl group of the benzoic acids and the nitrogen atoms in triazine and triazole rings, we observed the formation of an additional $\mathrm{H}$-bond between the carbonyl group of the acid and the hydrogen atom situated at the C4 position of the 1,2,3-triazole ring, which is allowed by the electropositive character of this triazole hydrogen. ${ }^{[4 d]}$

\section{Results and Discussion}

\section{Synthesis}

The 2,4,6-tris[1'-(4"'-butoxyphenyl)-1',2',3'-triazol-4'-yl)-1,3,5triazine core $\left(\mathrm{T}_{3} \mathrm{C}_{4}\right)$ was synthesized by a copper-catalyzed alkyne-azide cycloaddition (CuAAC) "click reaction". Since the required alkyne 2,4,6-tris(ethynyl)-1,3,5-triazine is unstable, a previously described "one-pot" procedure ${ }^{[16]}$ which uses the protected precursor 2,4,6-tris[(trimethylsilyl)ethynyl]-1,3,5triazine ${ }^{[18]}$ has been used. In this "one pot" reaction, the alkyne groups of 2,4,6-tris[(trimethylsilyl)ethynyl]-1,3,5-triazine are deprotected and made to react in situ with the aromatic azide in the presence of catalytic copper(I) at room temperature (scheme $1)$. The reaction gave the desired product in a moderate yield (33\%). The required aromatic azide, 1-azido-4-butoxybenzene, was synthesized by diazotization of 4-aminophenol followed by reaction with sodium azide ${ }^{[16]}$ (scheme 1 ). The acids A1-A3 were synthesized by known procedures previously reported. ${ }^{[\mathrm{c}]}$

The $\mathrm{H}$-bonded complexes were prepared by dissolving a mixture of the tris(triazolyl)triazine core and the corresponding benzoic acid derivative in a 1:3 proportion, respectively, in dichloromethane. After evaporation of the solvent by continuous stirring at room temperature, the obtained mixtures were subjected to a thermal treatment consisting on heating up to the isotropic liquid and then cooling down to room temperature. The thermally treated mixtures were observed by polarizing optical microscopy (POM), and they appeared as homogeneous materials with liquid crystalline behavior, which suggested that the complexes had been formed.

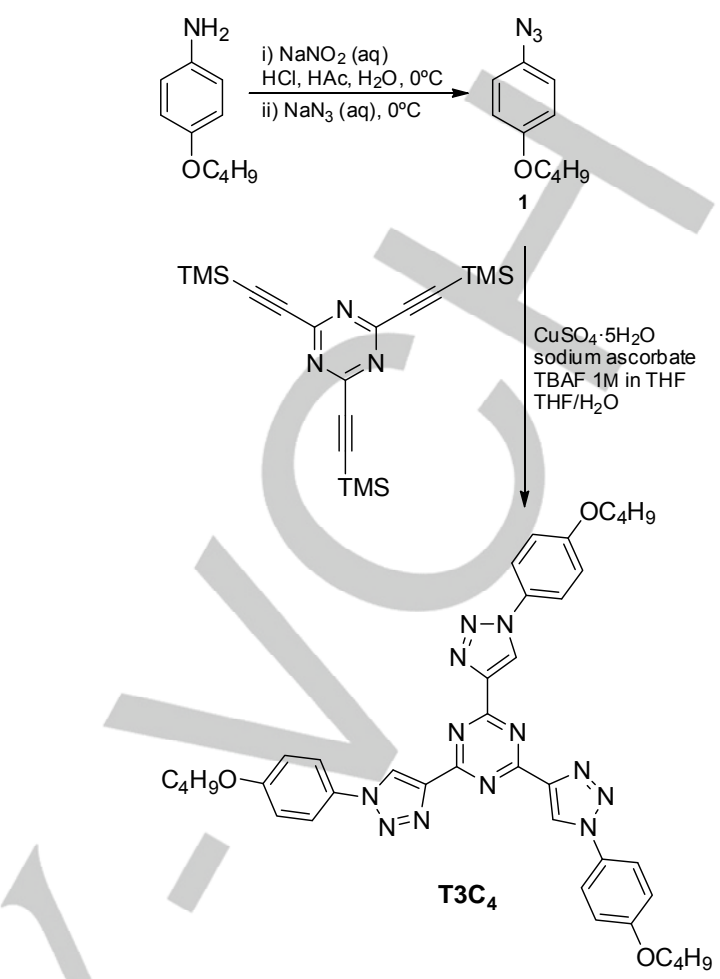

Scheme 1. Synthetic procedure for the preparation of the tris(triazolyl)triazine derivative $\mathrm{T}_{3} \mathrm{C}_{4}$.

\section{Study of the formation of $\mathrm{H}$-bonded complexes in solution}

In order to study the interaction between the $\mathrm{T}_{3} \mathrm{C}_{4}$ and the different benzoic acids in solution when mixed in a ratio $1: 3,{ }^{1} \mathrm{H}$ NMR experiments in $\left[D_{2}\right]$ dichloromethane were performed. Assuming that there is fast exchange between the complex and its components in solution, strong evidence of hydrogen-bonding interactions between the $\mathrm{T}_{3} \mathrm{C}_{4}$ core and acid molecules was found in the solution ${ }^{1} \mathrm{H}$ and ${ }^{13} \mathrm{C}$ NMR spectra of the complexes.

Figure 2 gathers the ${ }^{1} \mathrm{H}$ NMR spectra of the $\mathrm{T}_{3} \mathrm{C}_{4}$ core, the acid $\mathrm{A} 1$ and a mixture of both components in a 1:3 ratio. It can be observed that the signal corresponding to the hydrogen of triazole $\left(\mathrm{H}_{\mathrm{c}}\right)$ undergoes a shift from $8.90 \mathrm{ppm}$ in the pure $\mathrm{T}_{3} \mathrm{C}_{4}$ to $8.98 \mathrm{ppm}$ when the core and the acid are mixed, which indicates that this proton is interacting by $\mathrm{H}$-bond with the carbonyl group of the acid. Simultaneously, the aromatic protons of $\mathrm{T}^{3} \mathrm{C}_{4}\left(\mathrm{H}_{\mathrm{e}}\right.$ and $\mathrm{H}_{\mathrm{f}}$ ) show significant shielding. This upfield shift suggests aggregation of the complex due to m-stacking.

In order to check the possibility of the core to self-aggregate by $\pi$-stacking, ${ }^{1} \mathrm{H}$ NMR spectra of the pure $\mathrm{T}_{3} \mathrm{C}_{4}$ at different concentrations were recorded (Figure 3 ). On increasing the concentration, all the signals, including the triazole proton $\mathrm{H}_{\mathrm{c}}$, are clearly upfield shifted, which is in agreement with m-stacking aggregation.

Therefore, comparing Figure 2 and 3 at the same concentration of $\mathrm{T}_{3} \mathrm{C}_{4}$ core, $0.1 \mathrm{M}$, the presence of the acid in a 1:3 ratio causes further upfield shift of the aromatic protons $H_{e}$ and $H_{f}$, which can indicate that aggregation by $\pi$-stacking is 
even more favored upon formation of an $\mathrm{H}$-bonded complex. Interestingly, the triazole proton $\mathrm{H}_{\mathrm{c}}$ does not show upfield shift but downfield for the complex, and this confirms that this proton is involved in $\mathrm{H}$-bonding interaction.

Moreover, ${ }^{1} \mathrm{H}$ NMR spectra of the mixture $\mathrm{T}_{3} \mathrm{C}_{4}$ and $\mathrm{A} 1$ in a $1: 3$ ratio at different concentrations in $\left[D_{2}\right]$ dichloromethane were recorded (Figure 4). On increasing the concentration, all the signals corresponding to $\mathrm{T}_{3} \mathrm{C}_{4}$ are upfield shifted, which is in agreement with $\pi$-stacking aggregation of the complex, as it happened with the core itself.
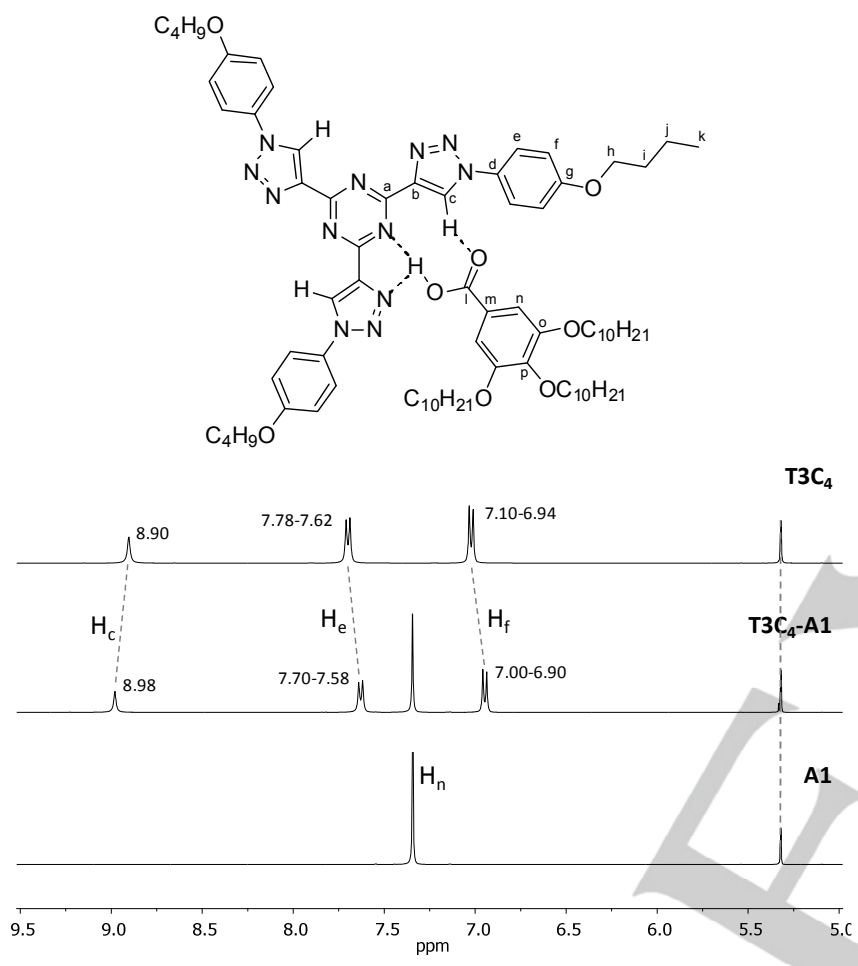

Figure 2. ${ }^{1} \mathrm{H}$ NMR spectra of the core $\mathrm{T}_{3} \mathrm{C}_{4}(0.1 \mathrm{M})$, the acid $\mathrm{A} 1(0.3 \mathrm{M})$ and their mixture in $\left[D_{2}\right]$ dichloromethane, maintaining these concentrations..

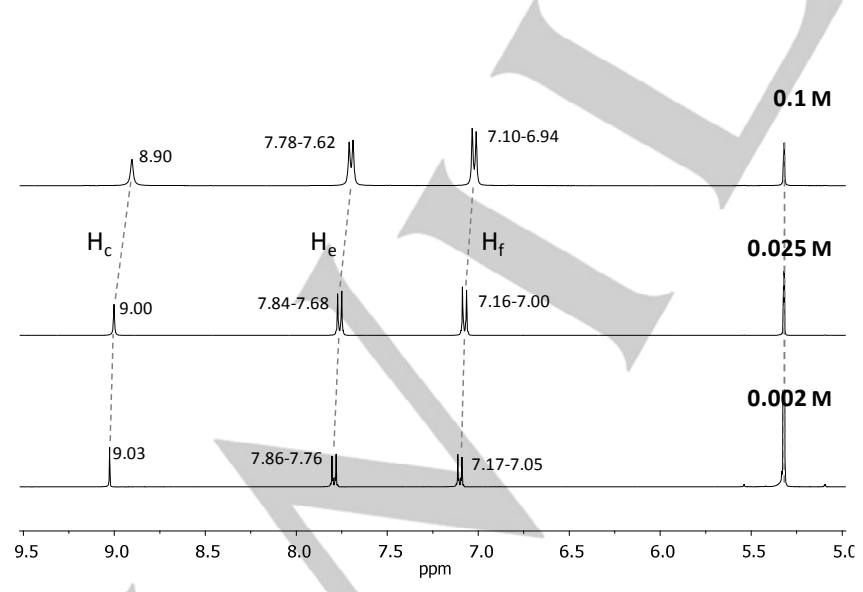

Figure 3. ${ }^{1} \mathrm{H}$ NMR spectra of the core $\mathrm{T}_{3} \mathrm{C}_{4}$ in $\left[\mathrm{D}_{2}\right]$ dichloromethane at different concentrations $(0.1 \mathrm{M}, 0.025 \mathrm{M}$ and $0.002 \mathrm{M})$.

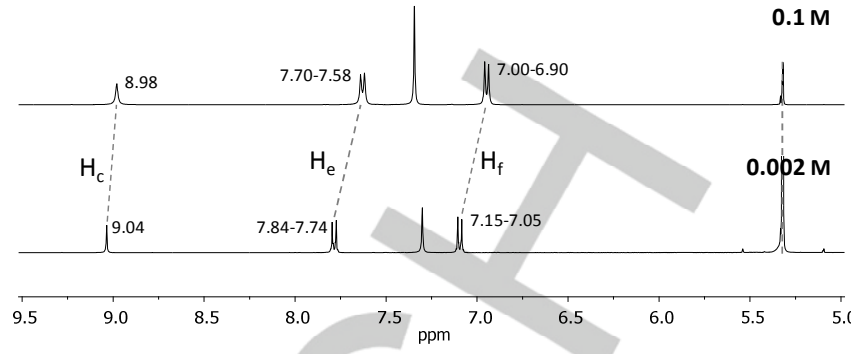

Figure 4. ${ }^{1} \mathrm{H}$ NMR spectra of the mixture $\mathrm{T}_{3} \mathrm{C}_{4}$ and $\mathrm{A} 1$ in a $1: 3$ ratio in $\left[D_{2}\right]$ dichloromethane at different concentrations $(0.1 \mathrm{M}$ and $0.002 \mathrm{M}$, referred to $\mathrm{T}_{3} \mathrm{C}_{4}$ ).

Similar results, which are included in the supporting information, were observed for mixtures of the core $\mathrm{T}_{3} \mathrm{C}_{4}$ and acids A2 (Figures S7, S8) or A3 (Figures S12, S13).

In addition, in order to determine the stoichiometry of the complexes in solution, the Job's plot method was applied to ${ }^{1} \mathrm{H}$ NMR experiments in $\left[D_{2}\right]$ dichloromethane solutions. The Job's plot for the hydrogen of the triazole group shows a maximum at $X_{A}=0,5$, which indicates that the core-acid association occurs in a $1: 1$ stoichiometry in $\left[D_{2}\right]$ dichloromethane solution (Figure $S 14$ ). This result is similar to those obtained for previously reported complexes between melamines and carboxylic acids, and does not preclude the formation of 1:3 complexes in the mesophase. ${ }^{[9]}$

\section{Thermal properties and mesomorphic behavior}

The thermal properties of the $\mathrm{H}$-bonded complexes and their individual components were studied by polarizing optical microscopy (POM) and differential scanning calorimetry (DSC).

The tris(triazolyl)triazine $\mathrm{T}_{3} \mathrm{C}_{4}$ is not a liquid crystal. It was obtained as a crystalline solid which melts at $173^{\circ} \mathrm{C}$ and then, on cooling, an amorphous solid with a glass transition about 60 ${ }^{\circ} \mathrm{C}$ is obtained. Acids $\mathrm{A} 1$ and $\mathrm{A} 2$ (with three alkoxylic chains, $\mathrm{OC}_{10} \mathrm{H}_{21}$ and $-\mathrm{OC}_{12} \mathrm{H}_{25}$, respectively) do not display mesomorphic properties. ${ }^{[19]}$ However, acid A3 exhibits hexagonal columnar mesomorphism ( $\left.\mathrm{Cr} 65 \mathrm{Col}_{\mathrm{h}} 144 \mathrm{I}\right)$, in which the stacking units consist on $\mathrm{H}$-bonded dimers. ${ }^{[8 c, 20]}$

As mentioned above, all the complexes are homogeneous materials with mesomorphic behavior within broad temperature intervals. Furthermore, mesomorphic properties are obtained from non-mesogenic components in the case of $\mathrm{T}_{3} \mathrm{C}_{4}-\mathrm{A} 1$ and $\mathrm{T}_{3} \mathrm{C}_{4}-\mathrm{A} 2$, what also evidences the formation of the $\mathrm{H}$-bonded complexes. Characteristic textures of columnar mesophases were observed by POM for all the complexes (Figure 5). The thermal properties (transition temperatures and enthalpies) of the $\mathrm{H}$-bonded complexes are given in table 1.

The complex $\mathrm{T}_{3} \mathrm{C}_{4}-\mathrm{A} 3$ can retain the mesophase at room temperature as deduced from the DSC cooling scan (Figure S17). However, for $\mathrm{T}_{3} \mathrm{C}_{4}-\mathrm{A} 1$ and $\mathrm{T}_{3} \mathrm{C}_{4}-\mathrm{A} 2$, the $\mathrm{DSC}$ thermograms are not fully clear. For these complexes, partial crystallization or partial separation of the components can be deduced from the corresponding DSC cooling scans. Nevertheless, the observations by POM clearly allow assessing that the phase separation does not occur, and homogeneous 
materials that uniformly melt to the isotropic liquid are obtained. The mesophases of complexes $\mathrm{T}_{3} \mathrm{C}_{4}-\mathrm{A} 1$ and $\mathrm{T}_{3} \mathrm{C}_{4}-\mathrm{A} 2$ are metastable at room temperature and they crystallize on heating as deduced from the appearance of cold crystallization processes in the corresponding DSC heating scans (Figures S15 and S16).
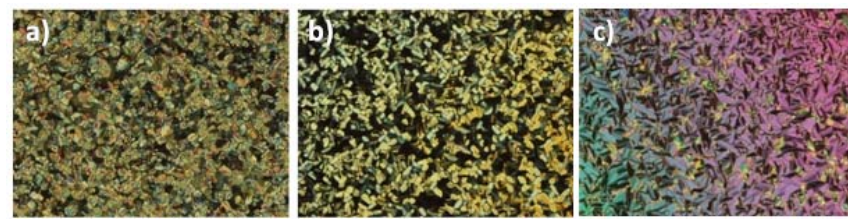

Figure 5. Microphotographs of the textures observed by POM for (a) $\mathrm{T}_{3} \mathrm{C}_{4}-\mathrm{A} 1$, $\mathrm{Col}_{\mathrm{h}}, 50{ }^{\circ} \mathrm{C}$ (cooling), (b) $\mathrm{T} 3 \mathrm{C}_{4}-\mathrm{A} 2, \mathrm{Col}_{\mathrm{h}}, 45{ }^{\circ} \mathrm{C}$ (cooling), and (c) $\mathrm{T}^{3} \mathrm{C}_{4}-\mathrm{A} 3, \mathrm{Col}_{\mathrm{h}}$, $122^{\circ} \mathrm{C}$ (cooling).

Table 1. Thermal properties of the $\mathrm{H}$-bonded complexes and structural parameters measured by X-ray diffraction of the respective columnar mesophases.

\begin{tabular}{|c|c|c|}
\hline Complex & Thermal properties $\left(T /{ }^{\circ} \mathrm{C},\left[\Delta H / \mathrm{kJ} \mathrm{mol}^{-1}\right]\right)^{[a]}$ & $\begin{array}{l}\text { Lattice } \\
\text { parameters }\end{array}$ \\
\hline $\mathrm{T} 3 \mathrm{C}_{4}-\mathrm{A} 1$ & $\begin{array}{l}\text { I } 71[2.8] \mathrm{Col}_{h} 9[0.7]^{[\mathrm{b}]} \mathrm{Col}_{h}+\mathrm{Cr} \\
\mathrm{Col}_{h}+\mathrm{Cr} 30[-1.4] \mathrm{Cr} 37[5.6] \mathrm{Col}_{h} 85[2.1] \mathrm{I}\end{array}$ & $a=33.5 \AA$ \\
\hline $\mathrm{T}_{3} \mathrm{C}_{4}-\mathrm{A} 2$ & $\begin{array}{l}\mathrm{I} 67[2.5] \mathrm{Col}_{\mathrm{h}} 20[19.1]^{[\mathrm{b}]} \mathrm{Col}_{\mathrm{h}}+\mathrm{Cr} \\
\mathrm{Col}_{\mathrm{h}}+\mathrm{Cr} 30[-19.3] \mathrm{Cr} 55[47.9] \mathrm{Col}_{\mathrm{h}} 82[1.5] \mathrm{I}\end{array}$ & $a=35.6 \AA$ \\
\hline $\mathrm{T}_{3} \mathrm{C}_{4}-\mathrm{A} 3$ & $\begin{array}{l}\text { I } 136[12.1] \mathrm{Col}_{h} \\
\mathrm{Col}_{\mathrm{h}} 142[12.4] \text { I }\end{array}$ & $\begin{array}{l}a=42.3 \AA \\
c=3.4 \AA\end{array}$ \\
\hline
\end{tabular}

[a] DSC data of the first cooling process and the second heating process at a rate of $10{ }^{\circ} \mathrm{C} \mathrm{min}^{-1}$. Temperatures at the maxima of the peaks are given. I: isotropic liquid; Colh: hexagonal columnar phase; Cr: crystalline phase. [b] Partial crystallization.

The textures observed by POM are characteristic of hexagonal columnar mesophases, although the assignment of the type of mesophase and the determination of the lattice parameters were achieved by X-ray diffraction studies (Table 1 ). $\mathrm{X}$-ray experiments were carried out on samples that were cooled from the isotropic liquid. For complex $\mathrm{T}_{3} \mathrm{C}_{4}-\mathrm{A} 3$, which can retain the mesophase, the experiments were performed at room temperature (Figure 6). For complexes $\mathrm{T}_{3} \mathrm{C}_{4}-\mathrm{A} 1$ and $\mathrm{T}_{3} \mathrm{C}_{4}-\mathrm{A} 2$, whose mesophases are metastable at room temperature, the experiments were carried out at higher temperatures (Figures S18 and S19), where the mesophases are known to be stable according to the DSC thermograms.

The X-ray patterns of all the three complexes contain a single diffraction maximum at small angles. In the absence of other reflections, it is difficult to unambiguously assign the type of mesophase on the basis of X-ray diffraction data alone. Nevertheless, similar behavior has been found in other structures previously described as hexagonal columnar phases, and it is due to a minimum in the form factor, which precludes the observation of peaks in this small-angle region. ${ }^{[8 c, 16,21]}$ Only one diffraction maximum could also be consistent with lamellar phases as those described for polycatenar disc-like ionic complexes with peripheral long tails. ${ }^{[22]}$ Unlike these ionic complexes, the peripheral long tails in the present complexes are contained in benzoic acid derivatives. These acids bring additional aromatic rings radiating from the tris(triazoline)triazine core that contribute to the planar disk-like core making it prone to $\pi$-stacking. Given the complex structure and according to the textures observed by POM, we suggest that these complexes show hexagonal columnar mesomorphism, Colh. All the complexes show in the wide-angle region a diffuse halo at $4.5 \AA$ due to the liquid-like order between the disordered aliphatic chains. Additionally, an outer diffuse halo at $3.4 \AA$ is observed for complex $\mathrm{T}_{3} \mathrm{C}_{4}-\mathrm{A} 3$, which is indicative of a periodic stacking distance along the columns (parameter $c$ ). The value of the parameter $c$ for this complex is in accordance to the stacking distance found in columnar mesophases of tris(triazolyl)triazines. ${ }^{[16]}$ Moreover, in a partially oriented diagram which was registered on a mechanically treated sample of $\mathrm{T}^{3} \mathrm{C}_{4}$ A3 (Figure 6b), this latter reflection is reinforced along the alignment direction, while the low-angle reflection is reinforced in the perpendicular direction. This pattern is consistent with a columnar mesophase in which columns are oriented along the rubbing direction.

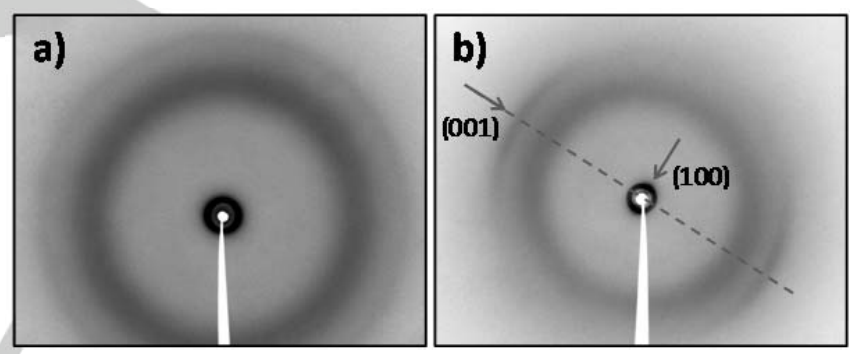

Figure 6. X-ray diffraction patterns of $\mathrm{T}_{3} \mathrm{C}_{4}-\mathrm{A} 3(\mathrm{a})$ room temperature and (b) room temperature, partially aligned sample: the reinforced reflections (arrows) and the rubbing direction (dashed line) are indicated.

Assuming that the low-angle maxima correspond to the (100) reflection of the corresponding hexagonal columnar mesophases, the lattice parameters, $a$, of the complexes were determined from these maxima. As it can be expected, the hexagonal lattice constant $a$ increases as the length of the aliphatic chain of the benzoic acid derivative is increased. Thus, for complex $\mathrm{T}_{3} \mathrm{C}_{4} \mathrm{~A} 2$, with twelve carbon atoms in each chain, the hexagonal parameter $a=35.6 \AA$ is larger than the value for complex $\mathrm{T}_{3} \mathrm{C}_{4}-\mathrm{A} 1, a=33.5 \AA$, with decyloxy chains. Furthermore, the hexagonal lattice constant measured for complex $\mathrm{T}_{3} \mathrm{C}_{4}-\mathrm{A} 3$ is significantly larger, $a=42.3 \AA$, because of the extended size of acid A3.

In addition, the density of the complexes was calculated on the basis of the parameters measured by X-ray diffraction. The relationship between the density $(\rho)$ of the complexes in the mesophase and the measured lattice parameters is given by the equation $\rho=(M \cdot Z) /\left(N_{A} \cdot V\right)$, where $M$ is the molar mass of the 
$1: 3$ complex, $Z$ is the number of molecules in the unit cell, $N_{A}$ is Avogadro's number, and $V$ is the unit cell volume $(V=a \cdot a \sqrt{3} / 2$ $\cdot c \cdot 10^{-24}$ ). The density of the complexes (on the assumption that $Z=1$ ) was calculated to be close to $1 \mathrm{~g} \mathrm{~cm}^{-3}$, which is reasonable for organic compounds, and thus it is in agreement with the formation of discotic 1:3 complexes with one complex per stacking unit.

\section{Study of the formation of the complexes in the mesophase}

Further confirmation of the formation of $1: 3$ complexes in the mesophase could be attained from studies performed in the mesophase, which were based on infrared spectroscopy (IR), solid state NMR and fluorescence spectroscopies.

As it was performed for X-ray experiments, the IR spectra of the complexes were recorded at temperatures at which the mesophases are known to be stable on cooling from the isotropic states: for complex $\mathrm{T}_{3} \mathrm{C}_{4}-\mathrm{A} 3$, the experiment was carried out at room temperature, and for complexes $\mathrm{T}_{3} \mathrm{C}_{4}-\mathrm{A} 1$ and $\mathrm{T}_{3} \mathrm{C}_{4}-\mathrm{A} 2$, the spectra were recorded at $60{ }^{\circ} \mathrm{C}$ (Figures S21 and S22).
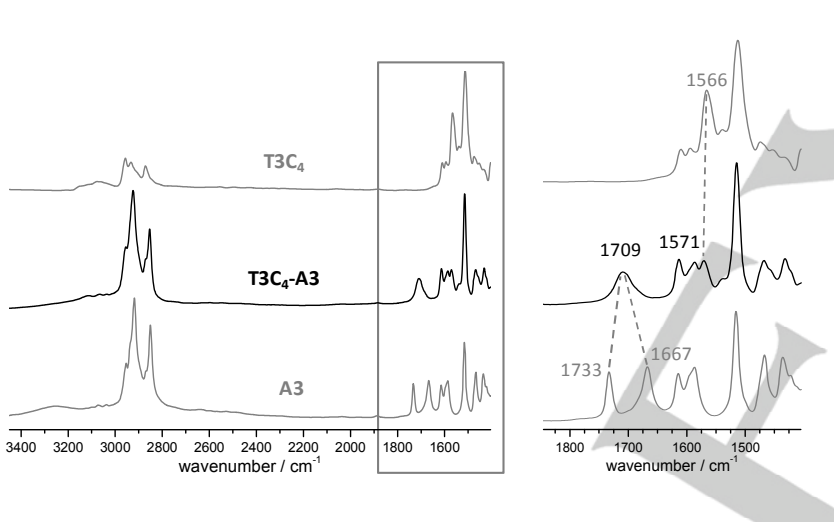

Figure 7. Infrared spectra of $\mathrm{T}_{3} \mathrm{C}_{4}, \mathrm{~A} 3$ and complex $\mathrm{T}_{3} \mathrm{C}_{4}-\mathrm{A} 3$ (room temperature) recorded on $\mathrm{KBr}$ pellets. On the right, a zoom in the 1850-1400 $\mathrm{cm}^{-1}$ region is shown.

As a representative example that evidences the formation of the $\mathrm{H}$-bonding associations, the infrared spectra of $\mathrm{T}_{3} \mathrm{C}_{4}, \mathrm{~A} 3$ and the corresponding 1:3 complex $\mathrm{T}_{3} \mathrm{C}_{4}-\mathrm{A} 3$ are very revealing and are shown in Figure 7. A significant difference between the $\mathrm{C}=\mathrm{O}$ stretching bands in the acid and in the complex spectra can be observed. In the acid spectrum, two $\mathrm{C}=\mathrm{O}$ stretching bands appear at $1667 \mathrm{~cm}^{-1}$ and $1733 \mathrm{~cm}^{-1}$, which correspond to the dimeric form and the free form of $A 3$, respectively. In the IR spectrum of complex $\mathrm{T}_{3} \mathrm{C}_{4}-\mathrm{A} 3$, however, a single band is observed at an intermediate position, at $1709 \mathrm{~cm}^{-1}$. Moreover, significant changes in the band corresponding to the hydroxyl group can be observed when the complex is formed. In the acid spectrum, two $\mathrm{O}-\mathrm{H}$ stretching bands appear: the typical broad band between 3600 and $2400 \mathrm{~cm}^{-1}$, due to the dimeric form of the acid, and an additional band between about 3550 and 3150 $\mathrm{cm}^{-1}$, which corresponds to the free form. In the spectrum of complex $\mathrm{T}_{3} \mathrm{C}_{4}-\mathrm{A} 3$ this latter band does not appear, and only the broad band related with hydrogen bonding interactions is observed. Additionally, the bands that correspond to the heterocyclic rings slightly shift to higher wavenumber (eg. from 1566 to $1571 \mathrm{~cm}^{-1}$ ) when the complex is formed.

The ${ }^{13} \mathrm{C}$ cross polarization magic-angle spinning $\left({ }^{13} \mathrm{C}\right.$ CPMAS) NMR spectrum could be recorded at room temperature in the $\mathrm{Col}_{\mathrm{h}}$ mesophase for complex $\mathrm{T}_{3} \mathrm{C}_{4}-\mathrm{A} 3$, providing strong evidence of the formation of the complex according to a 1:3 stoichiometry. Figure 8 shows the spectrum of this complex compared with those of its corresponding components, acid A3 and core $\mathrm{T}_{3} \mathrm{C}_{4}$.

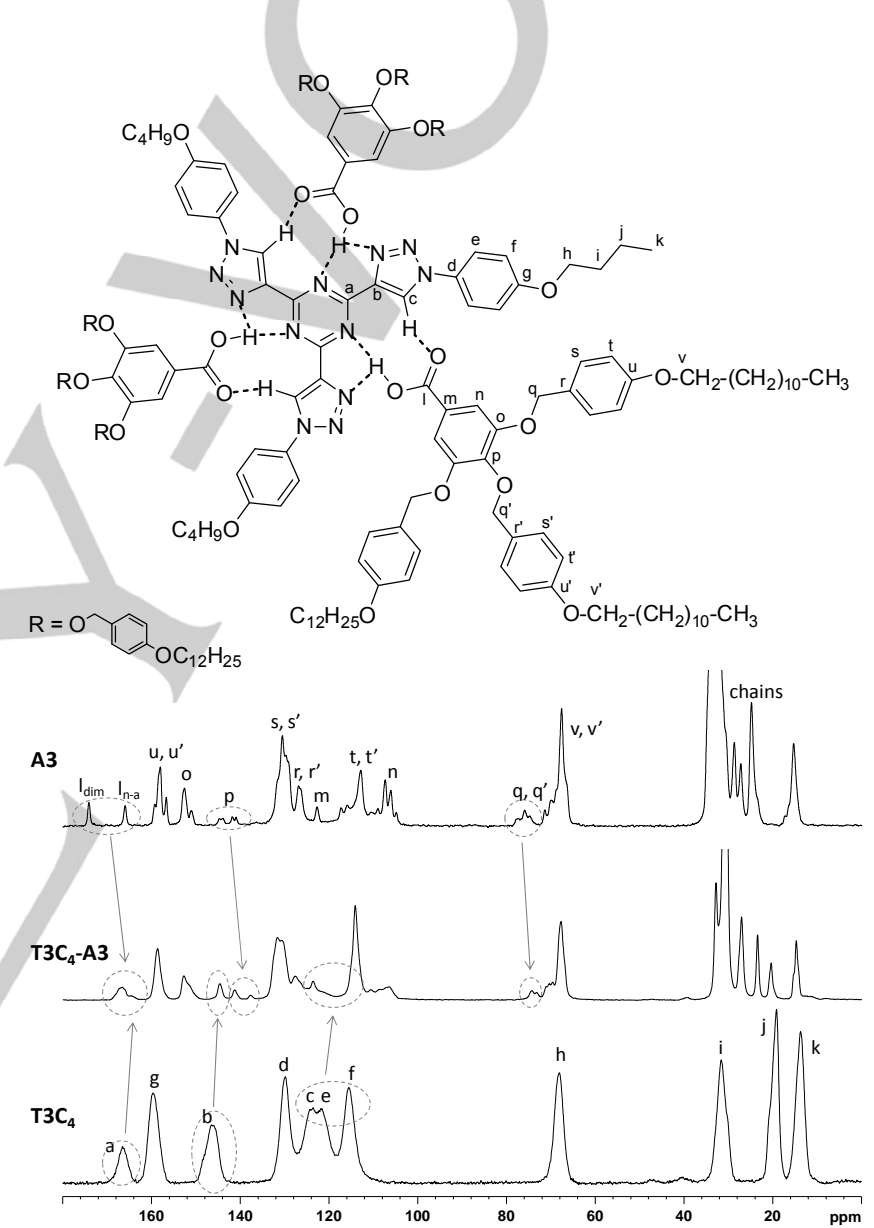

Figure 8. ${ }^{13} \mathrm{C}$ CPMAS NMR spectra of $\mathrm{T}_{3} \mathrm{C}_{4}, \mathrm{~A} 3$ and their corresponding 1:3 complex, $\mathrm{T}_{3} \mathrm{C}_{4}-\mathrm{A} 3$. The most representative signals that shift upon complexation are indicated. All the spectra were recorded at room temperature.

The spectrum of the acid A3 shows two signals corresponding to the carbon atom of the carbonyl group, at $172.2 \mathrm{ppm}$ and $166.0 \mathrm{ppm}$, which correspond to the dimeric form and the free form of $\mathrm{A} 3$, respectively. These signals are not visible in the ${ }^{13} \mathrm{C}$ NMR spectrum of the complex but, instead, a new signal appears overlapped with the carbon atom of the triazine ring. This signal can be interpreted to correspond to the carbon atom of the carbonyl group forming $\mathrm{H}$-bonding interactions with the core. Other signals of both the core and the acid are also shifted when the complex is formed in the bulk, 
and this can be related to differences in the stacking order of the complex with respect to the core or the acid, separately. In general, the signals corresponding to the core are shifted upfield upon complexation. Triazole carbons $\mathbf{b}$ and $\mathbf{c}$, aromatic carbons $\mathbf{e}$ and $\mathbf{f}$, and the carbons linked to the oxygen atom in the terminal chains, $\mathbf{h}$, are shifted upfield upon complexation. With respect to the acids, some of their aromatic signals slightly shift to lower fields upon formation of the complex. Finally, the signals of the aliphatic chains of both the acid and the core undergo significant changes upon complexation, likely due to conformational changes.

The comparative study of the photoluminescence of both the complexes and their corresponding pure components also revealed differences in their emission behavior (Table 2). The fluorescence spectra were recorded on films, which were prepared by cooling the compounds from their isotropic liquid state between quartz plates. The spectra of the individual components, core and acids, were recorded at room temperature in their solid phases obtained by cooling the isotropic liquid. As it was performed for X-ray and IR experiments, the fluorescence and excitation spectra of the complexes were recorded at temperatures at which the mesophases are known to be stable: for complex $\mathrm{T}_{3} \mathrm{C}_{4}-\mathrm{A} 3$ the experiments were carried out in the columnar mesophase at room temperature (Figures 9 and S27), and for complexes $\mathrm{T}_{3} \mathrm{C}_{4-}$ $\mathrm{A} 1$ and $\mathrm{T} 3 \mathrm{C}_{4}-\mathrm{A} 2$ the spectra were recorded at $60{ }^{\circ} \mathrm{C}$ (Figures S23-S26). The absorption spectrum of complex $\mathrm{T}_{3} \mathrm{C}_{4}-\mathrm{A} 3$ could be measured in the mesophase at room temperature and was similar to its excitation spectrum (Figure S28).

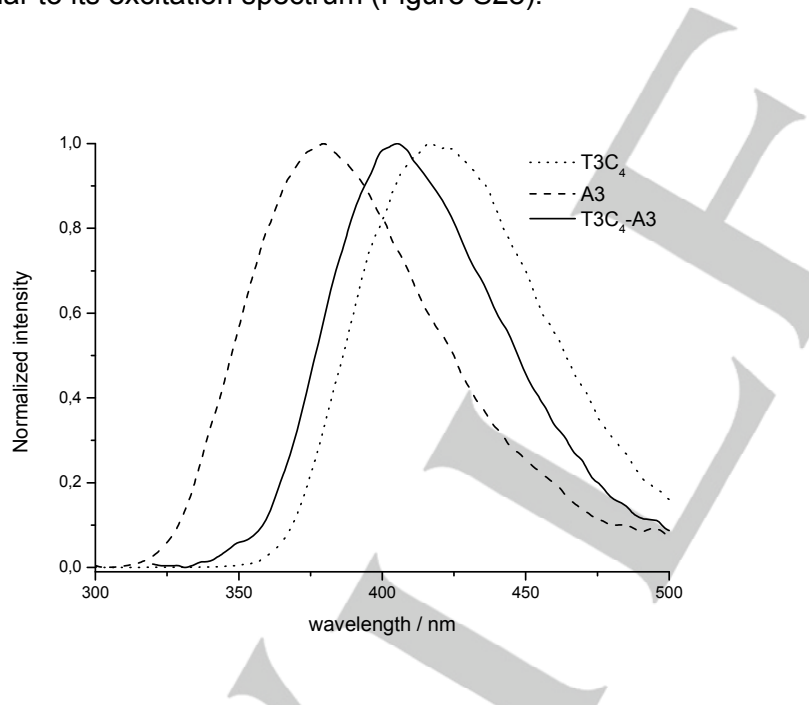

Figure 9. Emission spectra of $\mathrm{T}_{3} \mathrm{C}_{4}, \mathrm{~A} 3$ and complex $\mathrm{T}_{3} \mathrm{C}_{4}-\mathrm{A} 3$ in thin films at room temperature

The core $\mathrm{T}_{3} \mathrm{C}_{4}$ shows an emission band in the blue region of the visible spectrum $(423 \mathrm{~nm})$, while the acids show emission at lower wavelengths, in the UV region (344 or $380 \mathrm{~nm}$ ). In contrast, the fluorescence spectra of the complexes show a band at 405 $\mathrm{nm}$. The disappearance of the emission band of the acid and the observed red-shift support the formation of the $\mathrm{H}$-bonded complexes. ${ }^{[4 d]}$ This is interesting in terms of having an additional technique to control the formation and stability of these supramolecular complexes by simply recording the emission spectra of the film.

Table 2. Fluorescent data (excitation and emission wavelengths) of thin films

\begin{tabular}{lll}
\hline Compound & $\lambda$ exc $/ \mathrm{nm}$ & $\lambda \mathrm{em} / \mathrm{nm}$ \\
\hline $\mathrm{A} 1$ & 275 & 344 \\
$\mathrm{~A} 2$ & 275 & 344 \\
$\mathrm{~A} 3$ & 280 & 380 \\
$\mathrm{~T}_{3} \mathrm{C}_{4}$ & 286 & 423 \\
$\mathrm{~T}_{3} \mathrm{C}_{4}-\mathrm{A} 1$ & 290 & 405 \\
$\mathrm{~T}_{3} \mathrm{C}_{4}-\mathrm{A} 2$ & 290 & 405 \\
$\mathrm{~T}_{3} \mathrm{C}_{4}-\mathrm{A} 3$ & 290 & 405 \\
\hline
\end{tabular}

\section{Conclusions}

New supramolecular complexes based on $\mathrm{H}$-bonding interactions between a tris(triazolyl)triazine derivative $\left(\mathrm{T}_{3} \mathrm{C}_{4}\right)$ and three molecules of polycatenar benzoic acids (A1, A2, A3) have been prepared. When these components are mixed in $\left[D_{2}\right]$ dichloromethane in a $1: 3$ ratio, respectively, NMR experiments have proved the interaction between the hydrogen of the triazole ring of the tris(triazolyl)triazine core and the carboxylic acids. This interaction leads to the formation of an $\mathrm{H}$ bonded complex, being the 1:1 stoichiometry the species stable in solution, which additionally show significant tendency to selfaggregate by $\pi$-stacking.

In the bulk, all the three complexes, mainly formed by nonmesogenic components, show hexagonal columnar mesomorphism at different ranges of temperatures, as demonstrated by POM, DSC and X-ray diffraction experiments. This behavior is consistent with the formation of $\mathrm{T} 3 \mathrm{C}_{4}-\mathrm{A} 1, \mathrm{~T}_{3} \mathrm{C}_{4}$ $\mathrm{A} 2, \quad \mathrm{~T} 3 \mathrm{C}_{4}-\mathrm{A} 3$ complexes with a $1: 3$ stoichiometry. Further evidences of the formation of the 1:3 complexes have been obtained from the study of the mesomorphic materials by different techniques, such as infrared spectra, solid-state NMR $\left({ }^{13} \mathrm{C}\right.$ CPMAS) and fluorescence spectroscopy. These results suggest a decisive role of mesogenic driving forces (mainly $\pi-$ stacking) to help the formation of the 1:3 complex in the bulk.

Finally, the preparation and study of these complexes provides a versatile approach to ordered materials that can be readily prepared and easily modified in their periphery, in order to modulate their functionality. 


\section{Experimental Section}

\section{General remarks}

All reagents were purchased from Aldrich and used without further purification. Anhydrous dichloromethane and THF were purchased from Scharlab and dried by using a solvent purification system. ${ }^{1} \mathrm{H}$ NMR and ${ }^{13} \mathrm{C}$ NMR spectra were acquired on a Bruker AV400 spectrometer. The experiments were performed at room temperature in different deuterated solvents $\left(\mathrm{CDCl}_{3}\right.$ or $\left[\mathrm{D}_{2}\right]$ dichloromethane). Chemical shifts are given in ppm relative to TMS and the solvent residual peak was used as the internal standard. Solid-state NMR experiments were performed using a double resonance $\left({ }^{1} \mathrm{H}-\mathrm{X}\right)$ probe with a rotor of $2.5 \mathrm{~mm}$ diameter, and the spinning frequency was set to $15 \mathrm{kHz}$. Data were acquired at $298 \mathrm{~K}$ and chemical shifts are referenced to TMS. The ${ }^{1} \mathrm{H}$ and ${ }^{13} \mathrm{C}$ pulse length were 8 and $5.7 \mu \mathrm{s}$, respectively, and the CP contact time was $1.5 \mathrm{~ms}$. The recycle delay was $5 \mathrm{~s}$. The pulse sequence employed consisted of ramped cross-polarization with spinal-64 decoupling. Infrared spectra were recorded on a Bruker Vertex 70 FT-IR spectrometer. The samples were prepared on $\mathrm{KBr}$ pellets with a concentration of the product of $1-2 \%$ $(w / w)$. A temperature controller can be adapted in order to measure the spectra at different temperatures. Mass spectra were obtained on a MICROFLEX Bruker (MALDI+) spectrometer with a dithranol matrix. Elemental analyses were performed using a Perkin-Elmer $240 \mathrm{C}$ microanalyzer. The mesophases were examined by polarizing optical microscopy using a polarizing optical microscope Olympus BX51 equipped with an Olympus DP12 digital camera and connected to a Linkam THMS600 hot stage and a Linkam TMS94 controller. Transition temperatures and enthalpies were obtained by differential scanning calorimetry with DSC TA instruments Q-20 and Q-2000 at heating and cooling rates of $10{ }^{\circ} \mathrm{C} \mathrm{min}{ }^{-1}$. The apparatus were previously calibrated with indium $\left(156.6{ }^{\circ} \mathrm{C}, 28.44 \mathrm{~J} \mathrm{~g}^{-1}\right)$. Powder X-ray experiments were performed in a Pinhole diffractometer (Anton Paar) operating with a point focused $\mathrm{Ni}$-filtered $\mathrm{Cu}-\mathrm{Ka}$ beam. The samples were held in Lindemann glass capillaries ( 0.7 and $0.9 \mathrm{~mm}$ diameter) and heated with a variabletemperature attachment. The diffraction patterns were collected on photographic films. Fluorescence spectra were recorded with a PerkinElmer LS50B spectrophotometer. Films were prepared between two quartz plates by heating the compounds to their isotropic liquid and cooling to the experiment temperatures and they were measured by front-detection.

\section{Synthesis and characterization of $\mathrm{T}_{3} \mathrm{C}_{4}$}

1-azido-4-butoxybenzene (1): 4-butoxyaniline $(2.50 \mathrm{~g}, 15.1 \mathrm{mmol})$ was dissolved in an aqueous mixture consisting of $\mathrm{H}_{2} \mathrm{O}(40 \mathrm{~mL})$, glacial acetic acid $(90 \mathrm{~mL})$ and $\mathrm{HCl}$ conc. $(8 \mathrm{~mL}) . \mathrm{NaNO}_{2}(1.22 \mathrm{~g}, 17.7 \mathrm{mmol})$ dissolved in $\mathrm{H}_{2} \mathrm{O}(10 \mathrm{~mL})$ was slowly added to the mixture at $0{ }^{\circ} \mathrm{C}$. The mixture was stirred for 5 minutes and then $\mathrm{NaN}_{3}(1.10 \mathrm{~g}, 16.9 \mathrm{mmol})$ dissolved in $\mathrm{H}_{2} \mathrm{O}$ $(10 \mathrm{~mL})$ was slowly added. The reaction was stirred at $0^{\circ} \mathrm{C}$ for 90 minutes. Then, the mixture was extracted with $\mathrm{CH}_{2} \mathrm{Cl}_{2}$. The organic layers were combined and washed with an aqueous solution of $\mathrm{NaOH}(10 \%)$. The organic layer was dried over $\mathrm{MgSO}_{4}$ and the solvent was evaporated. The crude oil was dried at $50{ }^{\circ} \mathrm{C}$ under vacuum for 4 hours and it was purified by column chromatography with silica gel as stationary phase and hexane as eluent to give the product as an orange oil. Yield: 93\% $(2.71 \mathrm{~g}) .{ }^{1} \mathrm{H}$ NMR $\left(400 \mathrm{MHz}, \mathrm{CDCl}_{3}\right) \delta 6.97-6.92$ (m AA'BB', $\left.2 \mathrm{H}, \mathrm{ArH}\right)$, $6.91-6.86$ (m AA'BB', 2H, ArH), $3.94\left(\mathrm{t}, \mathrm{J}=6.5 \mathrm{~Hz}, 2 \mathrm{H}, \mathrm{OCH}_{2}\right.$ ), $1.83-$ $1.70\left(\mathrm{~m}, 2 \mathrm{H}, \mathrm{CH}_{2}\right), 1.55-1.43\left(\mathrm{~m}, 2 \mathrm{H}, \mathrm{CH}_{2}\right), 0.98\left(\mathrm{t}, \mathrm{J}=7.4 \mathrm{~Hz}, 3 \mathrm{H}, \mathrm{CH}_{3}\right)$ ${ }^{13} \mathrm{C} \mathrm{NMR}\left(100 \mathrm{MHz}, \mathrm{CDCl}_{3}\right) \delta 156.7,132.2,120.1,115.9,68.2,31.4$, 19.4, 14.0. IR ( $\left.\mathrm{NaCl}, \mathrm{cm}^{-1}\right): 2959\left(\mathrm{Csp}^{3}-\mathrm{H}\right), 2109\left(\mathrm{~N}_{3}\right), 1504(\mathrm{Ar}), 1245$ (C-O) 2,4,6-tris[1'-(4''-butoxyphenyl)-1',2',3'-triazol-4'-yl)-1,3,5-triazine (T3C $\left.\mathbf{C}_{4}\right): \quad 2,4,6$-tris[(trimethylsilyl)ethynyl]-1,3,5-triazine ${ }^{[18]}(1.00 \mathrm{~g}, \quad 2.7$ $\mathrm{mmol})$, (1) (1.61 g, $8.4 \mathrm{mmol})$, sodium ascorbate $(0.16 \mathrm{~g}, 0.8 \mathrm{mmol})$ and $\mathrm{CuSO}_{4} \cdot 5 \mathrm{H}_{2} \mathrm{O}(0.10 \mathrm{~g}, 0.4 \mathrm{mmol})$ were dissolved in a mixture of $\mathrm{THF} / \mathrm{H}_{2} \mathrm{O}$ $1 / 1(35 \mathrm{~mL})$ under argon atmosphere. The mixture was stirred at room temperature for 3 minutes and then tetrabutylammonium fluoride (TBAF) $1 \mathrm{M}$ in THF $(8.4 \mathrm{~mL}, 8.4 \mathrm{mmol})$ was added. The reaction was stirred at room temperature in dark for 16 hours. Then, water $(20 \mathrm{~mL})$ was added to the reaction mixture and it was extracted with $\mathrm{CH}_{2} \mathrm{Cl}_{2}(3 \times 60 \mathrm{~mL})$. The combined organic layers were dried over $\mathrm{MgSO}_{4}$ and the solvent was evaporated. The residue was purified by column chromatography on silica gel, gradually increasing the polarity of the eluent from $\mathrm{CH}_{2} \mathrm{Cl}_{2}$ to $\mathrm{CH}_{2} \mathrm{Cl}_{2}$ /ethyl acetate 9.5/1 and further recrystallization from ethanol, giving the product as a yellowish solid. Yield: $33 \%(0.66 \mathrm{~g}) .{ }^{1} \mathrm{H}$ NMR (400 $\mathrm{MHz},\left[\mathrm{D}_{2}\right]$ dichloromethane) $\delta 9.03(\mathrm{~s}, 3 \mathrm{H}, \mathrm{H}$ triazole), $7.86-7.76(\mathrm{~m}, 6 \mathrm{H}$, $\mathrm{ArH}), 7.17-7.05(\mathrm{~m}, 6 \mathrm{H}, \mathrm{ArH}), 4.06\left(\mathrm{t}, \mathrm{J}=6.5 \mathrm{~Hz}, 6 \mathrm{H}, \mathrm{OCH}_{2}\right), 1.86-$ $1.77\left(\mathrm{~m}, 6 \mathrm{H}, \mathrm{CH}_{2}\right), 1.59-1.48\left(\mathrm{~m}, 6 \mathrm{H}, \mathrm{CH}_{2}\right), 1.01\left(\mathrm{t}, \mathrm{J}=7.4 \mathrm{~Hz}, 9 \mathrm{H}, \mathrm{CH}_{3}\right)$. ${ }^{13} \mathrm{C}$ NMR $\left(100 \mathrm{MHz},\left[\mathrm{D}_{2}\right]\right.$ dichloromethane) $\delta 167.3,160.5,146.4,130.3$, 126.2, 122.7, 115.9, 68.8, 31.8, 19.8, 14.2. IR $\left(\mathrm{KBr}, \mathrm{cm}^{-1}\right): 2958\left(\mathrm{Csp}^{3}-\mathrm{H}\right)$, $2932\left(\mathrm{Csp}^{3}-\mathrm{H}\right), 2872\left(\mathrm{Csp}^{3}-\mathrm{H}\right), 1611,1566,1513$ (arC-C, triazole), 1249 (C-O), 1169 (C-O). MS (MALDI+, dithranol): 749.4 [M+Na] ${ }^{+}, 1476.1$ $\left[\mathrm{M}_{2}+\mathrm{Na}\right]^{+}$. Elemental analysis: calculated (\%) for $\mathrm{C}_{39} \mathrm{H}_{42} \mathrm{~N}_{12} \mathrm{O}_{3} \cdot \mathrm{H}_{2} \mathrm{O}: \mathrm{C}$ 62.89, H 5.95, N 22.57; found: C 62.76, H 5.99, N 22.23.

\section{Synthesis and characterization of A1, A2 and A3.}

The acids A1-A3 were synthesized by following procedures described elsewhere. ${ }^{[8 c, 19-20]}$

\section{Preparation of the H-bonded complexes}

Before the preparation of the mixtures, the pure components were dissolved in $\mathrm{CH}_{2} \mathrm{Cl}_{2}$ and filtered, and the solvent was evaporated. The hydrogen-bonded complexes were prepared from $\mathrm{CH}_{2} \mathrm{Cl}_{2}$ solution of a mixture of $\mathbf{T} 3 \mathbf{C}_{4}$ and the corresponding carboxylic acid in a 1:3 proportion. The solvent was evaporated by stirring at room temperature, and the mixtures were heated to their isotropic states and then cooled to room temperature before being used for further experiments.

\section{Acknowledgements}

This work was financially supported by the MINECO-FEDER funds (projects MAT2012-38538-CO3-01 and CTQ2012-35692), and the Gobierno de Aragón-FSE (E04 research group). B.F. acknowledges the DGA for the EPIF grant. Authors would like to acknowledge the use of "Servicios Científico-Técnicos" of CEQMA (UZ-CSIC).

Keywords: H-bonding interactions • columnar liquid crystals • self-assembly $\bullet \mathrm{NMR} \cdot$ luminescence

[1] a) T. Kato, J. M. J. Frechet, J. Am. Chem. Soc. 1989, 111, 8533-8534; b) T. Kato, J. M. J. Frechet, Macromolecules 1989, 22, 3818-3819; c) T. Kato, Macromolecules 1990, 23, 360-360; d) M. J. Brienne, J. Gabard, J. M. Lehn, I. Stibor, J. Chem. Soc., Chem. Commun. 1989, 1868-1870.

[2] a) T. Kato, N. Mizoshita, K. Kishimoto, Angew. Chem. Int. Ed. 2006, 45, 3868; b) T. Kato, T. Yasuda, Y. Kamikawa, M. Yoshio, Chem. Commun. 2009 729-739; c) C. Tschierske, Angew. Chem. Int. Ed. 2013, 52, 8828-8878. [3] B. Roy, N. De, K. C. Majumdar, Chem. Eur. J. 2012, 18, 14560-14588. 
[4] a) A. Kraft, A. Reichert, R. Kleppinger, Chem. Commun. 2000, 1015-1016; b) F. Osterod, L. Peters, A. Kraft, T. Sano, J. J. Morrison, N. Feeder, A. B. Holmes, J. Mater. Chem. 2001, 11, 1625-1633; c) H. K. Lee, H. Lee, Y. H. Ko, Y. J. Chang, N. K. Oh, W. C. Zin, K. Kim, Angew. Chem. Int. Ed. 2001, 40, 2669-2671; d) M.-H. Ryu, J.-W. Choi, H.-J. Kim, N. Park, B.-K. Cho, Angew. Chem. Int. Ed. 2011, 50, 5736-5739; e) S. Park, M.-H. Ryu, T. J. Shin, B.-K. Cho, Soft Matter 2014, 10, 5804-5809; f) J.-F. Xiong, S.-H. Luo, J.-P. Huo, J.Y. Liu, S.-X. Chen, Z.-Y. Wang, J. Org. Chem. 2014, 79, 8366-8373.

[5] D. González-Rodríguez, A. P. H. J. Schenning, Chem. Mater. 2011, 23 , 310-325

[6] T. Jarosz, M. Lapkowski, P. Ledwon, Macromol. Rapid Commun. 2014, 35, 1006-1032

[7] a) D. Goldmann, D. Janietz, R. Festag, C. Schmidt, J. H. Wendorff, Liq. Cryst. 1996, 21, 619-623; b) C. H. Lee, T. Yamamoto, Tetrahedron Lett. 2001, 42, 3993-3996; c) C. J. Lee, S. J. Lee, J. Y. Chang, Tetrahedron Lett. 2002, 43 3863-3866; d) W. M. Shu, S. Valiyaveettil, Chem. Commun. 2002, 1350-1351; e) H. Lee, D. Kim, H. K. Lee, W. F. Qiu, N. K. Oh, W. C. Zin, K. Kim, Tetrahedron Lett. 2004, 45, 1019-1022; f) H. C. Holst, T. Pakula, H. Meier, Tetrahedron 2004, 60, 6765-6775; g) K. C. Majumdar, N. De, B. Roy, A. Bhaumik, Liq. Cryst. 2010, 37, 1459-1464; h) H. Detert, M. Lehmann, H. Meier Materials 2010, 3, 3218-3330; i) M. Lehmann, Top. Curr. Chem. 2012, 318 193-223

[8] a) D. Goldmann, R. Dietel, D. Janietz, C. Schmidt, J. H. Wendorff, Liq. Cryst. 1998, 24, 407-411; b) D. Goldmann, D. Janietz, C. Schmidt, J. H. Wendorff, J. Mater. Chem. 2004, 14, 1521-1525; c) J. Barberá, L. Puig, J. L. Serrano, T. Sierra, Chem. Mater. 2004, 16, 3308-3317; d) J. Barberá, L. Puig, P. Romero, J. L. Serrano, T. Sierra, Chem. Mater. 2005, 17, 3763-3771; e) A. Kohlmeier, D. Janietz, Liq. Cryst. 2007, 34, 289-294; f) C. Domínguez, B. Heinrich, B. Donnio, S. Coco, P. Espinet, Chem. Eur. J. 2013, 19, 5988-5995. [9] a) L. Álvarez, J. Barberá, L. Puig, P. Romero, J. L. Serrano, T. Sierra, J. Mater. Chem. 2006, 16, 3768-3773; b) J. Barberá, L. Puig, P. Romero, J. L. Serrano, T. Sierra, J. Am. Chem. Soc. 2006, 128, 4487-4492; c) F. Vera, R. M. Tejedor, P. Romero, J. Barberá, M. B. Ros, J. L. Serrano, T. Sierra, Angew. Chem. Int. Ed. 2007, 46, 1873-1877; d) F. Vera, J. Barberá, P. Romero, J. L. Serrano, M. B. Ros, T. Sierra, Angew. Chem. Int. Ed. 2010, 49, 4910-4914; e) A. A. Vieira, H. Gallardo, J. Barberá, P. Romero, J. L. Serrano, T. Sierra, J. Mater. Chem. 2011, 21, 5916-5922.

[10] a) H. C. Kolb, M. G. Finn, K. B. Sharpless, Angew. Chem. Int. Ed. 2001, 40, 2004-2021; b) V. V. Rostovtsev, L. G. Green, V. V. Fokin, K. B. Sharpless, Angew. Chem. Int. Ed. 2002, 41, 2596-2599.
[11] M. Juricek, P. H. J. Kouwer, A. E. Rowan, Chem. Commun. 2011, 47 8740-8749.

[12] B. Schulze, U. S. Schubert, Chem. Soc. Rev 2014, 43, 2522-2571.

[13] a) Y. Hua, A. H. Flood, Chem. Soc. Rev 2010, 39, 1262-1271; b) J. Cai, J. L. Sessler, Chem. Soc. Rev 2014, 43, 6198-6213.

[14] F. García, J. Aragó, R. Viruela, E. Ortí, L. Sánchez, Org. Biomol. Chem. 2013, 11, 765-772.

[15] a) M.-H. Ryu, J.-W. Choi, B.-K. Cho, J. Mater. Chem. 2010, 20, 18061810; b) B.-K. Cho, S.-H. Kim, Soft Matter 2014, 10, 553-559; c) N. Hu, R. Shao, Y. Shen, D. Chen, N. A. Clark, D. M. Walba, Adv. Mater. 2014, 26 2066-2071; d) J. Kim, S. Cho, B.-K. Cho, Chem. Eur. J. 2014, 20, 1273412739; e) C. P. Umesh, S. Gangarapu, A. T. M. Marcelis, H. Zuilhof, Liq. Cryst. 2014, 1-11.

[16] E. Beltrán, J. L. Serrano, T. Sierra, R. Giménez, Org. Lett. 2010, 12, 1404-1407.

[17] E. Beltrán, J. L. Serrano, T. Sierra, R. Giménez, J. Mater. Chem. 2012, 22, 7797-7805.

[18] M. Sonoda, A. Inaba, K. Itahashi, Y. Tobe, Org. Lett. 2001, 3, 2419-2421.

[19] a) C. Mertesdorf, H. Ringsdorf, Liq. Cryst. 1989, 5, 1757-1772; b) C. Lin, H. Ringsdorf, M. Ebert, R. Kleppinger, J. H. Wendorff, Liq. Cryst. 1989, 5, 1841-1847.

[20] a) V. Percec, D. Schlueter, Y. K. Kwon, J. Blackwell, M. Moller, P. J. Slangen, Macromolecules 1995, 28, 8807-8818; b) V. Percec, C. H. Ahn, W. D. Cho, A. M. Jamieson, J. Kim, T. Leman, M. Schmidt, M. Gerle, M. Moller, S. A. Prokhorova, S. S. Sheiko, S. Z. D. Cheng, A. Zhang, G. Ungar, D. J. P. Yeardley, J. Am. Chem. Soc. 1998, 120, 8619-8631.

[21] a) H. X. Zheng, B. Xu, T. M. Swager, Chem. Mater. 1996, 8, 907-911; b) A. Hayer, V. de Halleux, A. Kohler, A. El-Garoughy, E. W. Meijer, J. Barberá, J. Tant, J. Levin, M. Lehmann, J. Gierschner, J. Cornil, Y. H. Geerts, J. Phys. Chem. B 2006, 110, 7653-7659; c) E. Cavero, S. Uriel, P. Romero, J. L. Serrano, R. Giménez, J. Am. Chem. Soc. 2007, 129, 11608-11618; d) A. Pérez, J. L. Serrano, T. Sierra, A. Ballesteros, D. de Saá, J. Barluenga, J. Am. Chem. Soc. 2011, 133, 8110-8113.

[22] a) J. Kadam, C. F. J. Faul, U. Scherf, Chem. Mater. 2004, 16, 3867-3871 b) Y. Zakrevskyy, B. Smarsly, J. Stumpe, C. F. J. Faul, Phys. Rev. E 2005, 71, 021701. 


\section{Entry for the Table of Contents}

Layout 2:

\section{FULL PAPER}

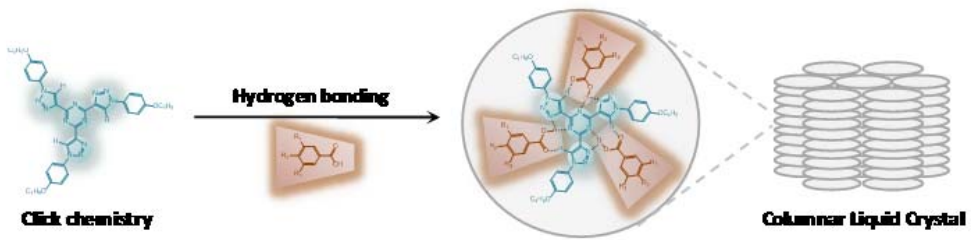

Beatriz Feringán, Pilar Romero, José Luis Serrano, Raquel Giménez* and Teresa Sierra*

Page No. - Page No.

Supramolecular columnar liquid crystals by hydrogen bonding between a clicked star-shaped s-triazine and benzoic acids

A new supramolecular synthon, based on tris(triazolyl)triazine, is able to interact by $\mathrm{H}$-bonding with benzoic acids and self-organize in columns 